LIMA et al. (2010)

\title{
AVALIAÇÃO DO POTENCIAL FITORREMEDIADOR DA MAMONA (Ricinus communis L) UTILIZANDO EFLUENTE SINTÉTICO CONTENDO CHUMBO
}

\author{
Anita Maria de Lima \\ Engenheira Química, aluna do Programa de Pós Graduação em Engenharia Química da \\ Universidade Federal do Rio Grande do Norte. anita@eq.ufrn.br \\ Josette Lourdes de Sousa Melo \\ Profa. do Depto de Engenharia Química, Universidade Federal do Rio Grande do Norte \\ josette@eq.ufrn.br. \\ Henio Normando de Souza Melo \\ Professor do Departamento de Engenharia Química, Universidade Federal do Rio Grande \\ do Norte. Campus Universitário, CEP: 59000-000, Natal (RN). henio @eq.ufrn.br \\ Fabíola Gomes de Carvalho \\ Professora do Instituto Federal de Educação Tecnológica do Rio Grande do Norte \\ fgcarvalho@cefetrn.edu.br
}

\section{RESUMO}

Os estudos de novas formas para o tratamento de efluentes domésticos e industriais vêm aumentando gradativamente no Brasil, neste contexto destacam-se as correntes que defendem a atenuação natural e a biorremediação. Por essas razões, em anos recentes, passou-se a dar preferência a métodos in situ, os quais são mais econômicos e perturbam menos o ambiente. Uma técnica de remediação natural é a fitorremediação que, aplica-se à utilização de vegetação (árvores, arbustos, plantas rasteiras e aquáticas) e de sua microbiota com o fim de remover, degradar ou isolar substâncias tóxicas ao ambiente. $\mathrm{O}$ presente trabalho teve como objetivo testar o capacidade de fitorremediação da mamona (Ricinus Communis L.) na redução das concentrações de chumbo presente em efluente sintético, cujas características simulam aquelas encontradas em um dos principais efluentes da indústria de exploração do petróleo, a água de produção tratada. O delineamento experimental utilizado no estudo foi o de blocos inteiramente casualizado com a variação das concentrações de chumbo distribuídas em quatro tratamentos: $0 \mu \mathrm{g} / \mathrm{L}$ (T1), $250 \mu \mathrm{g} / \mathrm{L}$ (T2), $500 \mu \mathrm{g} / \mathrm{L}$ (T3), $1000 \mu \mathrm{g} / \mathrm{L}$ (T4). Na análise dos dados foi aplicado o teste estatístico ANOVA para a comparação das médias nos tratamentos. A avaliação realizada nas concentrações de chumbo no lixiviado indicou que ocorreram remoções máximas de $67,42 \%, 87,34 \%$ e $94,74 \%$ para os tratamentos T2, T3 e T4, respectivamente. A retenção do chumbo nos tecidos (sistema radicular, caule e folhas) da mamona indicou que a planta apresentou boa capacidade de bioacumular o chumbo.

PALAVRAS-CHAVE: Fitorremediação, Chumbo, Mamona. 


\title{
ASSESSMENT OF POTENTIAL PHYTOREMEDIATION OF CASTOR BEAN (RICINUS COMMUNIS L.) USING SYNTHETIC EFFLUENT CONTAINING \\ LEAD
}

\begin{abstract}
Studies of new way for the treatment of domestic sewage and industrial have been increasing in Brazil, in this context is the current defending natural attenuation and bioremediation. For these reasons, in recent years, it moved to give preference to in situ methods, which are more economical and less disturb the environment. A natural remediation technique is phytoremediation that apply to the use of plant systems (trees, shrubs, creepers and water) and microorganism in order to remove, degrade or isolate toxic substances to the environment. This study aimed to test the potential for phytoremediation of castor bean (Ricinus communis L.) in reducing concentrations of lead in synthetic sewage, whose characteristics simulate those found in a major industry effluents of oil exploration, water production treated. The experimental design used in the study blocks was randomized to the variation of lead concentrations distributed in four treatments: $0 \mu \mathrm{g}$ / L (T1), $250 \mu \mathrm{g} / \mathrm{L}$ (T2), $500 \mu \mathrm{g} / \mathrm{L}$ (T3), $1000 \mu \mathrm{g} / \mathrm{L}$ (T4). The data analysis was applied ANOVA to compare the means for treatments. The assessment carried out in the lead concentrations in the leachate indicated that there were removals maximum $67.42 \%$, $87.34 \%$ and $94.74 \%$ for $\mathrm{T} 2, \mathrm{~T} 3$ and $\mathrm{T} 4$, respectively. The retention of lead in tissues (roots, stems and leaves) of castor indicated that the plant showed good ability to bioaccumulate lead.
\end{abstract}

KEY WORDS: Phytoremediation, Lead, Castor bean. 


\section{AVALIAÇÃO DO POTENCIAL FITORREMEDIADOR DA MAMONA (Ricinus communis L) UTILIZANDO EFLUENTE SINTÉTICO CONTENDO CHUMBO.}

\section{INTRODUÇÃO}

A problemática ambiental vem ganhando, ao longo dos anos, maior destaque em todos os setores da sociedade. $\mathrm{O}$ desenvolvimento de pesquisas que visam atenuar ou até mesmo eliminar os impactos ambientais proporcionados pelas ações antropogênicas, sobretudo pelo reflexo direto dos resíduos industriais nos compartimentos bióticos como solo, água e ar, ganharam maior espaço nos ambientes acadêmicos.

As idéias preservacionistas vêm sendo amplamente difundidas em todo o mundo, proporcionando à sociedade a exigência de legislações mais rigorosas quanto às emissões de poluentes. Neste sentido, o estabelecimento de concentrações mínimas dos elementos considerados tóxicos pelos órgãos ambientais, associado a multas severas para os infratores, impulsionaram os setores produtivos a investir em tecnologias visando $o$ tratamento e padronização dos seus efluentes e resíduos.

Os estudos de novas formas para o tratamento de efluentes domésticos e industriais vêm aumentando gradativamente no Brasil, neste contexto destacam-se as correntes que defendem a atenuação natural e a biorremediação. Entretanto, a implantação de sistemas de tratamento de efluentes ou redução de elementos tóxicos que são baseados na utilização dos mecanismos naturais esbarra na escassez de dados sobre os mecanismos que regem estes processos.

Os métodos químicos e físicos tradicionais de tratamento da água e do solo, como extração com solvente, oxiredução e incineração são bastante dispendiosos e oferecem riscos de contaminação secundária, pois o material contaminado tem que ser transportado ao local de tratamento. Por essas razões, em anos recentes, passou-se a dar preferência a métodos in situ, os quais são mais econômicos e perturbam menos o ambiente.

Uma técnica de remediação natural é a fitorremediação que, segundo Pletsh et al (1999), aplica-se à utilização de sistemas de tratamento que tem como elemento principal a vegetação (árvores, arbustos, plantas rasteiras e aquáticas) e sua microbiota com o fim de remover, degradar ou isolar substâncias tóxicas ao ambiente.

Segundo Andrade (2007) a fitorremediação apresenta grande versatilidade, podendo ser utilizada para remediação de meio aquoso, ar ou solo, com variantes que dependem dos objetivos a serem atingidos. A técnica envolve mecanismos como:

- Fitoextração: após a absorção do poluente contido no meio, ocorre o armazenamento no tecido vegetal, o que facilita o descarte do material.

- Fitrotransformação ou fitodegradação: o poluente sofre bioconversão no interior das plantas ou em sua superfície, passando a formas menos tóxicas (catabolismo ou anabolismo).

- Fitovolatilização: o poluente é absorvido e convertido em forma volátil, que é liberada na atmosfera.

- Fitoestimulação: a presença das plantas estimula a biodegradação microbiana mediante exsudatos radiculares e/ou fornecimento de tecidos vegetais. 
- Fitoestabilização: o poluente é imbolizado por meio de sua lignificação ou humificação.

Nesse contexto utilizar os mecanismos da fitorremediação com a utilização de plantas que além de apresentar capacidade de acumular contaminantes e ainda de ter potencial econômico, vem a ser um estratégia ambiental promissora, caracterizando-se dessa forma como reuso planejado ou sustentável.

Costa e Barros Junior (2005) ressaltam que, o reúso de água servida tem tomado relevante importância. Desde os anos sessenta, diversos países têm investido pesado em diferentes formas de reaproveitamento das águas servidas e/ou menos exigentes em termos de qualidade. No Brasil, essa prática ainda não sensibilizou a maioria da população e nem sequer foi difundida entre ela. Poucos exemplos poderiam ser relacionados com respeito ao reúso de água no Brasil. Apenas algumas Indústrias localizadas no Estado de São Paulo e alguns Projetos Piloto, no Nordeste brasileiro, com finalidade para reúso agrícola, têm avançado nessa área.

A exploração de petróleo gera como efluente imediato a água produzida ou água de produção, que, mesmo após tratamento para posterior descarte no oceano ou reinjeção nos poços, ainda apresenta concentrações de poluentes tais como metais pesados e hidrocarbonetos em níveis que podem impactar o meio ambiente. Entre os metais presentes nesses efluentes estão o chumbo, cromo, cádmio, arsênico, bário e mercúrio. No Rio Grande do Norte a quantidade de água de produção tratada descartada do mar é, segundo Silva (2002), da ordem de $60.000 \mathrm{~m} 3 /$ dia.

A mamoneira, mais conhecida como "carrapateira", "rícino", ou " planta christi" é uma planta muito exótica de origem afro-asiática, nativa e muito resistente ela é encontrada em grande quantidade na Etiópia, na região do Sennaar e Kordofan e na Índia. No Brasil a mamona foi trazida pelos portugueses com a finalidade de utilizar seu óleo para iluminação e lubrificação dos eixos das carroças. O clima tropical e, predominante no Brasil, facilitou o seu alastramento, (MATOS, 2007). A mamona pode ser considerada a principal oleaginosa para produção de biodiesel, por ser de fácil cultivo, de baixo custo e por ter resistência à seca, adaptando-se muito bem a forte exposição ao sol, altas temperaturas, requerendo no mínimo $500 \mathrm{~mm}$ de chuvas para seu crescimento e desenvolvimento normal, sendo assim indicada para regiões semi-áridas (PESSOA et al, 2007).

O presente trabalho teve como objetivo testar a capacidade de fitorremediação da mamona (Ricinus Communis L.) na redução das concentrações de chumbo presente em efluente sintético, cujas características simulam aquelas encontradas em um dos principais efluentes da indústria de exploração do petróleo, a água de produção tratada.

\section{METODOLOGIA}

Este trabalho foi conduzido nos domínios do Campus Central da Universidade Federal do Rio Grande do Norte (UFRN), mais precisamente na área externa do Laboratório de Engenharia Ambiental e Controle de Qualidade (LEACQ), unidade interligada ao Departamento de Engenharia Química localizado no Núcleo de Tecnologia, do referido Campus, no período de 28 de agosto a 4 de novembro de 2008. 
O solo utilizado no experimento foi o arenoso, de granulometria uniforme $(2 \mathrm{~mm})$, que para funcionar apenas como meio suporte inerte, foi submetido a sucessivas lavagens e seco em estufa com circulação de ar a $60{ }^{\circ} \mathrm{C}$. Foi utilizado 13 kilogramas de solo que foram acondicionados em vasos de 15 litros de capacidade máxima. Para propiciar a coleta do lixiviado, foram instalados drenos na parte lateral inferior de cada vaso.

As sementes de mamona, da variedade BRS Energia, foram cedidas pela Empresa de Pesquisa Agropecuária do Rio Grande do Norte (EMPARN). As mudas foram desenvolvidas nos vasos, da seguinte forma: três sementes de mamona em cada vaso, após a emergência das plantas realizou-se o desbaste, permanecendo as mudas mais desenvolvidas e com as mesmas características de altura em todos os vasos.

O delineamento experimental utilizado no estudo foi o de blocos inteiramente casualizado com a variação das concentrações de chumbo distribuídas em quatro tratamentos: $0 \mu \mathrm{g} / \mathrm{L}$ (T1), $250 \mu \mathrm{g} / \mathrm{L}$ (T2), $500 \mu \mathrm{g} / \mathrm{L}$ (T3), $1000 \mu \mathrm{g} / \mathrm{L}$ (T4), com 4 réplicas para cada tratamento, totalizando 16 parcelas. $\mathrm{Na}$ análise dos dados foi aplicado o teste estatístico ANOVA para a comparação das médias nos tratamentos. A Figura 1 apresenta a representação do delineamento proposto.

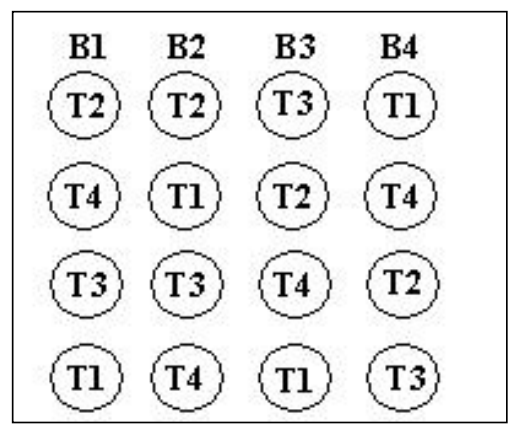

Figura 1 - Distribuição dos tratamentos nos vasos com o delineamento por blocos inteiramente casualizados.

Na preparação dos efluentes sintéticos, foram observadas as concentrações dos elementos tóxicos existentes nos efluentes naturais originados na indústria do petróleo. Foi utilizada água do mar na proporção de $0,5 \%$, para reproduzir a quantidade de cloretos presentes no efluente característico de água de produção tratada. Para suprir as deficiências nutricionais do solo foram adicionados elementos nutrientes cuja composição está apresentada na Tabela 1 abaixo.

Tabela 1: Composição do efluente sintético.

\begin{tabular}{|c|c|c|c|c|}
\hline \multicolumn{2}{|c|}{ Nutriente } & \multicolumn{2}{|c|}{ Micronutriente } & \multirow{2}{*}{$\begin{array}{l}\text { Tratamento/Concentra } \\
\text { ção de chumbo }\end{array}$} \\
\hline Sais & Concentração & Elemento & Concentração & \\
\hline $\mathrm{KH}_{2} \mathrm{PO}_{4}$ & $0,36 \mathrm{mg} / \mathrm{L}$ & Boro & $0,50 \mu \mathrm{g} / \mathrm{L}$ & $\mathrm{T} 1: \quad 0 \mu \mathrm{g} / \mathrm{L}$ \\
\hline $\mathrm{MgSO}_{4}$ & $0,120 \mathrm{mg} / \mathrm{L}$ & Cobre & $0,02 \mu \mathrm{g} / \mathrm{L}$ & $\mathrm{T} 2: \quad 250 \mu \mathrm{g} / \mathrm{L}$ \\
\hline $\mathrm{CaCl}_{2}$ & $0,110 \mathrm{mg} / \mathrm{L}$ & Manganês & $0,50 \mu \mathrm{g} / \mathrm{L}$ & T3: $500 \mu \mathrm{g} / \mathrm{L}$ \\
\hline $\mathrm{NH}_{4} \mathrm{NO}_{3}$ & $0,080 \mathrm{mg} / \mathrm{L}$ & Molibdênio & $0,001 \mu \mathrm{g} / \mathrm{L}$ & $\mathrm{T} 4: 1000 \mu \mathrm{g} / \mathrm{L}$ \\
\hline $\mathrm{MgNO}_{3}$ & $0,086 \mathrm{mg} / \mathrm{L}$ & Zinco & $0,05 \mu \mathrm{g} / \mathrm{L}$ & \\
\hline & & Ferro & $5 \mu \mathrm{g} / \mathrm{L}$ & \\
\hline
\end{tabular}


As concentrações de chumbo no lixiviado foram determinadas por espectrofotometria utilizando o método da ditizona preconizado pelo APHA (2005). Na determinação do metal no solo, raiz e parte aérea foi utilizada a espectrometria de absorção atômica com o equipamento Varian modelo AA240.

\section{RESULTADOS}

Foram analisados o lixiviado, o solo, as raízes e a parte aérea (folhas e caule), sob a perspectiva das concentrações de chumbo remanescente no sistema solo planta.

\section{- Avaliação da concentração de chumbo no lixiviado}

Os efluentes drenados nas parcelas que receberam os tratamentos com as concentrações de chumbo foram coletados e analisados por espectrofotometria utilizando o método da ditizona para determinação de chumbo. Os dados obtidos foram submetidos à análise de variância ANOVA a níveis de significância de 5\% e 1\% (Tabela 2). Essa avaliação indicou que os tratamentos apresentaram diferenças significativas nos dois níveis de significância adotados, indicando que houve influência de um ou mais tratamentos nos resultados obtidos.

Tabela 2: Análise de variância da remoção de chumbo nos tratamentos testados a um nível de significância de $1 \%$ e $5 \%$.

\begin{tabular}{|l|c|c|c|c|c|c|}
\hline \multirow{2}{*}{ Fonte da variação } & \multirow{2}{*}{$\begin{array}{c}\text { Soma dos } \\
\text { quadrados }\end{array}$} & \multirow{2}{*}{$\begin{array}{c}\text { Graus de } \\
\text { liberdade }\end{array}$} & Média dos & \multicolumn{3}{|c|}{ Teste F } \\
\cline { 6 - 8 } & & & & $\mathrm{F}$ & $\begin{array}{c}\text { F crít. } \\
(1 \%)\end{array}$ & $\begin{array}{c}\text { F crit. } \\
(5 \%)\end{array}$ \\
\hline Entre grupos & 5545,50 & 2 & 2772,75 & 18,44 & 6,36 & 3,68 \\
\hline Dentro dos grupos & 2255,85 & 15 & 150,39 & & & \\
\hline Total & 7801,34 & 17 & & & & \\
\hline
\end{tabular}

A avaliação das diferenças entre as médias de remoção dos tratamentos entre os grupos realizada pelo teste de Tukey aos níveis de 5\% e $1 \%$ de significância, permitiu identificar que os percentuais de remoção obtidas no tratamento T2 teve influência significativa no estudo, os demais tratamentos (T3 e T4), não apresentaram diferenças significativas entre as suas médias de remoção.

O acompanhamento das remoções de chumbo, em relação ao desenvolvimento das plantas (Figuras 2a, 2b e 2c), indicam que, a remoção de chumbo teve um comportamento crescente nos primeiros 30 centímetros de altura da planta, a partir desse estágio do desenvolvimento as remoções foram menores, coincidindo com a estabilização do crescimento das mamoneiras. $\mathrm{O}$ ajuste polinomial de ordem 2 foi o mais adequado para representar esse comportamento. Contudo em todos os tratamentos foram observadas remoções na ordem de $60 \%$ e $80 \%$ para os tratamentos T2 e T3, respectivamente, e de $90 \%$ para o tratamento $\mathrm{T} 4$. 
LIMA et al. (2010)

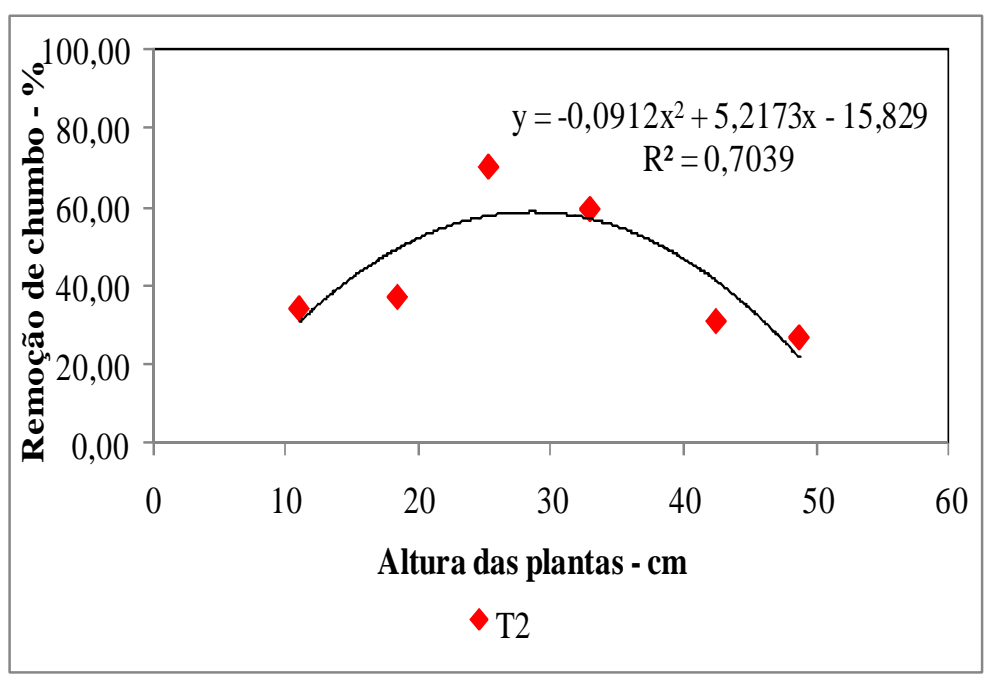

(2a)

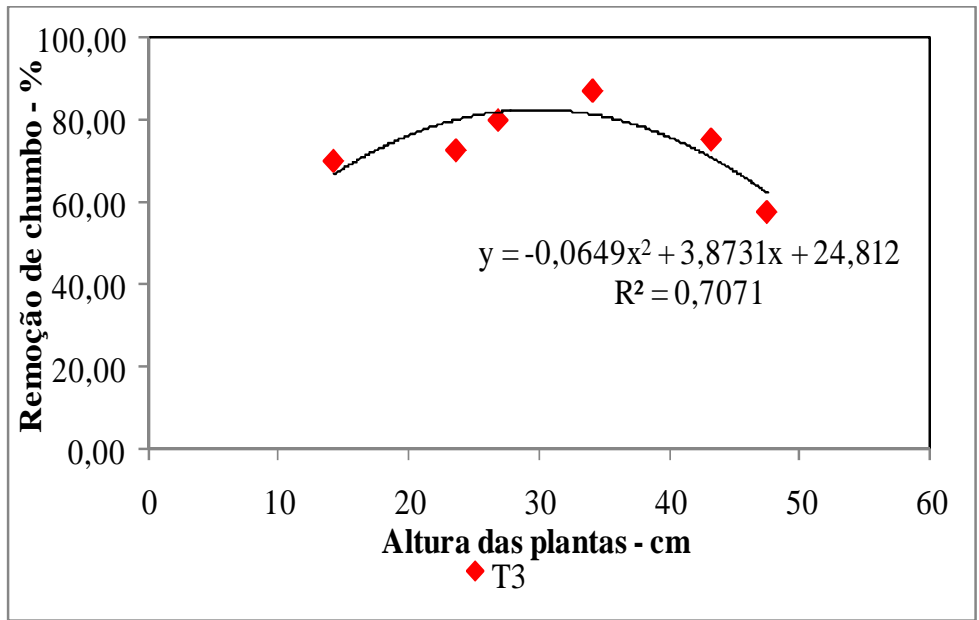

(2b)

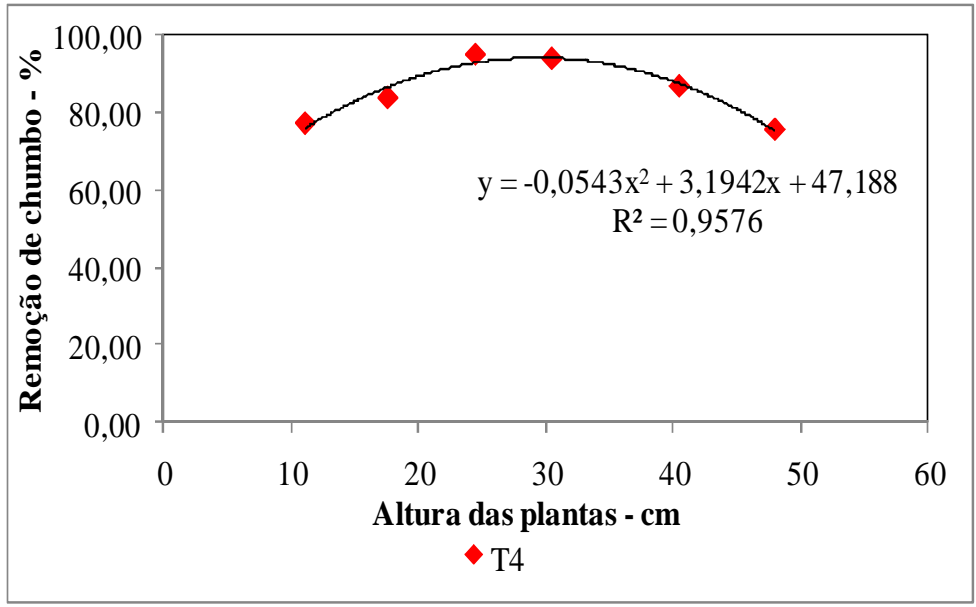

(2c)

Figura 2: Acompanhamento do percentual da remoção de chumbo em relação ao desenvolvimento das plantas expresso em altura (a, b e c). 
- Avaliação da concentração de chumbo no solo, raiz e parte aérea (caule + folhas)

As concentrações de chumbo no sistema solo-planta foi determinada por absorção atômica. A análise de variância ANOVA com testes de significância a 5\% e 1\%, indicaram que não foi observada diferenças significativas nos dados obtidos para solo e parte aérea, o mesmo não ocorrendo para os dados obtidos no sistema radicular, de acordo com o apresentado na Tabelas 3.

Tabela 3: Análise de variância da concentração de chumbo nas raízes nos tratamentos testados a um nível de significância de $1 \%$ e $5 \%$.

\begin{tabular}{|c|c|c|c|c|c|c|}
\hline \multirow[b]{2}{*}{ Fonte da variação } & \multirow{2}{*}{$\begin{array}{l}\text { Soma dos } \\
\text { quadrados }\end{array}$} & \multirow{2}{*}{$\begin{array}{l}\text { Graus de } \\
\text { liberdade }\end{array}$} & \multirow{2}{*}{$\begin{array}{l}\text { Média dos } \\
\text { quadrados }\end{array}$} & \multicolumn{3}{|c|}{ Teste F } \\
\hline & & & & $\mathrm{F}$ & $\begin{array}{l}\text { Fcrit. } \\
(1 \%)\end{array}$ & $\begin{array}{l}\text { F crit. } \\
(5 \%)\end{array}$ \\
\hline Entre grupos & 304570,2 & 2 & 152285,1 & 9,94 & 8,02 & 4,26 \\
\hline Dentro dos grupos & 137820,2 & 9 & 15313,35 & & & \\
\hline Total & 442390,4 & 11 & & & & \\
\hline
\end{tabular}

O teste de Tukey aos níveis de 5\% e 1\% de significância, permitiu identificar que as concentrações de chumbo obtidas no tratamento T2 teve influência significativa no estudo, os demais tratamentos (T3 e T4), não apresentaram diferenças significativas entre as suas médias de concentração.

A retenção do chumbo aplicado no solo seguiu comportamento linear em relação as concentrações de chumbo presentes nos tratamentos propostos. A Figura 3 ilustra essa avaliação.

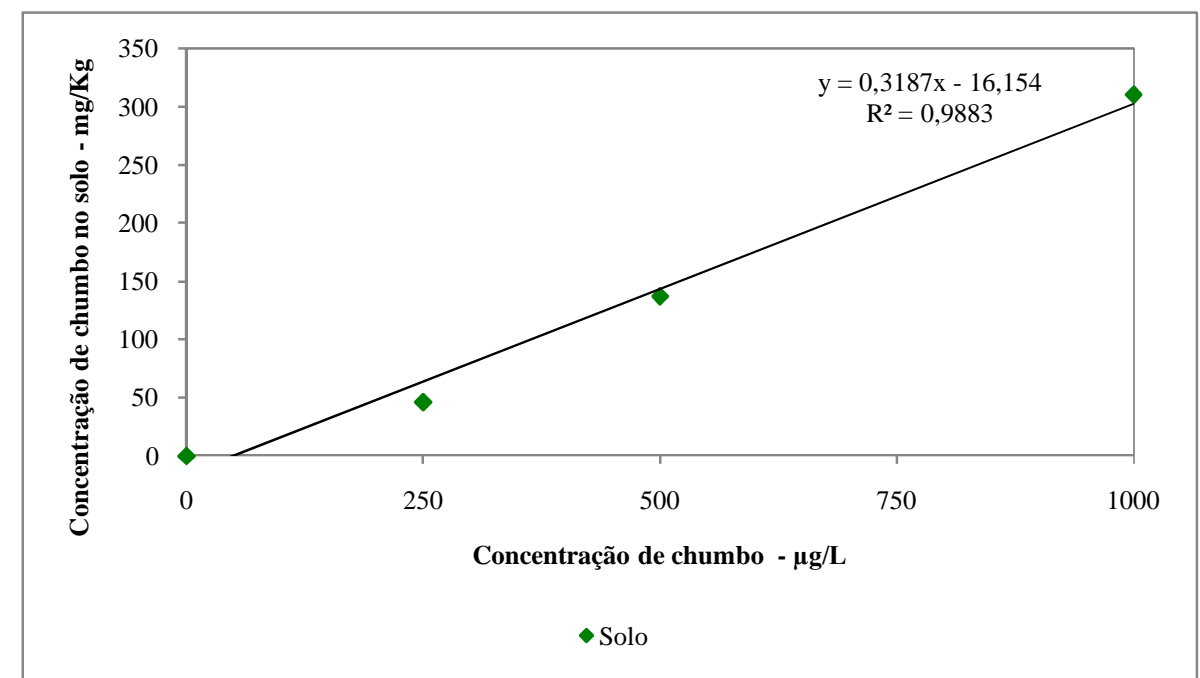

Figura 3: Conteúdo de chumbo no solo após a aplicação dos efluentes.

O conteúdo de chumbo identificado nas raízes seguiu comportamento polinomial de grau 2 , ou seja, neste estudo, a incorporação do contaminante nas raízes seguiu comportamento quadrático positivo (Figura 4). Em relação às concentrações testadas, essa observação é importante pois indica que a mamona apresenta boa capacidade de retenção do metal chumbo no sistema radicular. Segundo Larcher (2000), a absorção de elementos metálicos pelas células, particularmente pelas raízes, é facilitada por mecanismos próprios de transporte e acumulação. Nesse sentido o mecanismo envolvido foi a fitoextração, que 
segundo Andrade et al (2007) é a capacidade do tecido vegetal, reter o contaminante. Em baixas concentrações, o $\mathrm{Pb}$ move-se na raiz,predominantemente, via apoplasto e através do córtex e acumula-se perto da endoderme. A endoderme age como uma barreira parcial para a translocação do $\mathrm{Pb}$ das raízes para a parte aérea (Romeiro, 2007).

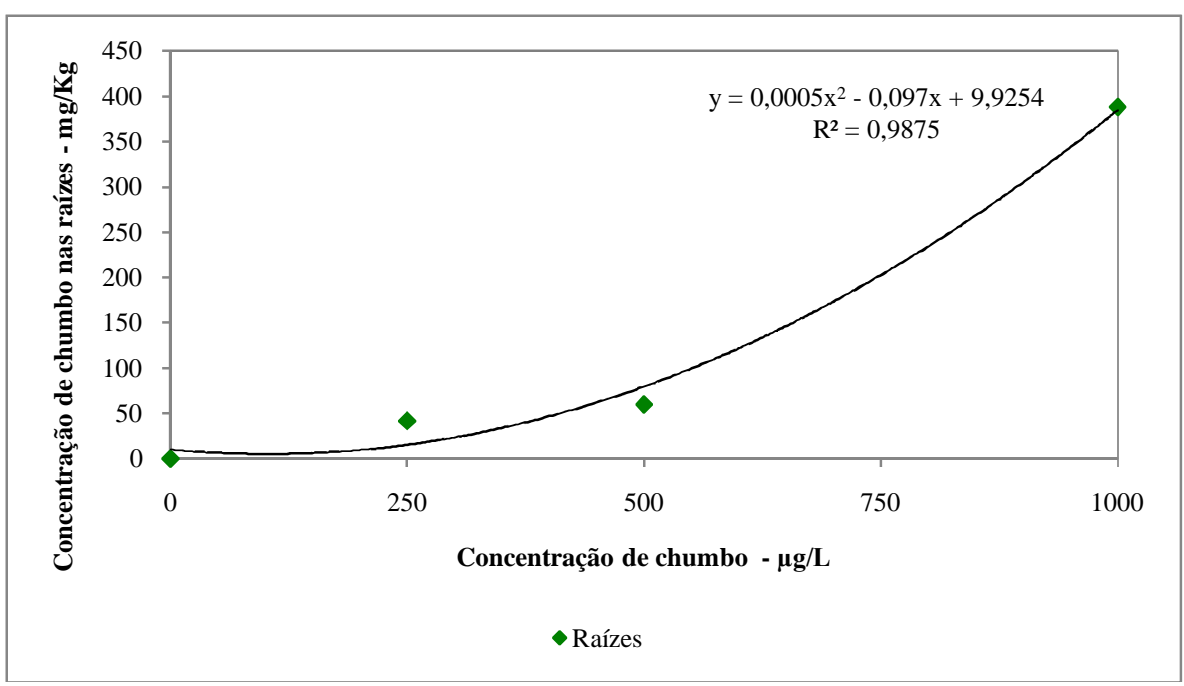

Figura 4: Conteúdo de chumbo nas raízes após a aplicação dos efluentes.

As concentrações de chumbo encontradas na parte aérea (caule + folhas), apresentou ajuste polinomial de ordem 2, com evolução negativa, considerando todas as concentrações testadas.

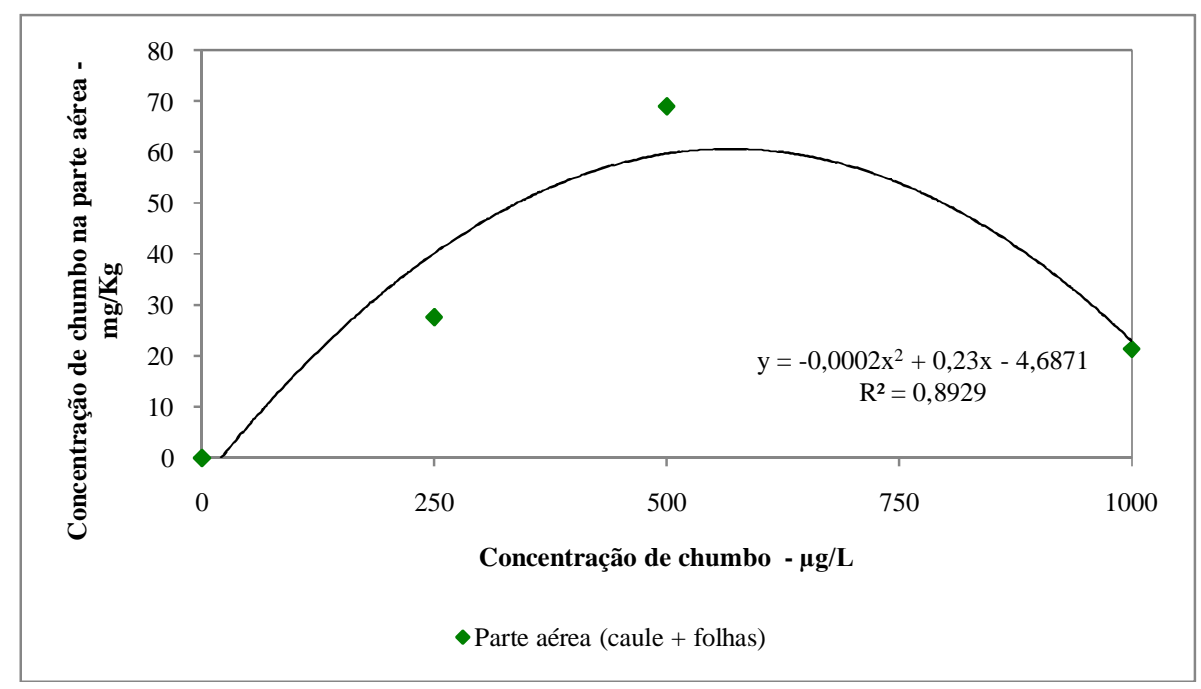

Figura 5: Conteúdo de chumbo na parte aérea após a aplicação dos efluentes.

A comparação dos dados obtidos para os compartimentos solo, raiz e parte aérea, indicam que $60 \%$ do que foi aplicado nos tratamentos T2 e T4 foi imobilizado no sistema radicular e na parte aérea, com relação ao tratamento T3 o percentual foi de 50\% para os mesmos compartimentos.

O balanço de massa realizado em todos os tratamentos sob a perspectiva da quantidade de chumbo aplicado durante o tempo de avaliação permitiu calcular a remoção global de cada 
sistema. A partir dessa avaliação se observa que, para os tratamentos T2 e T3 a remoção global foi na ordem de $50 \%$, e na ordem de $80 \%$ para o tratamento T4 (Figura 6).

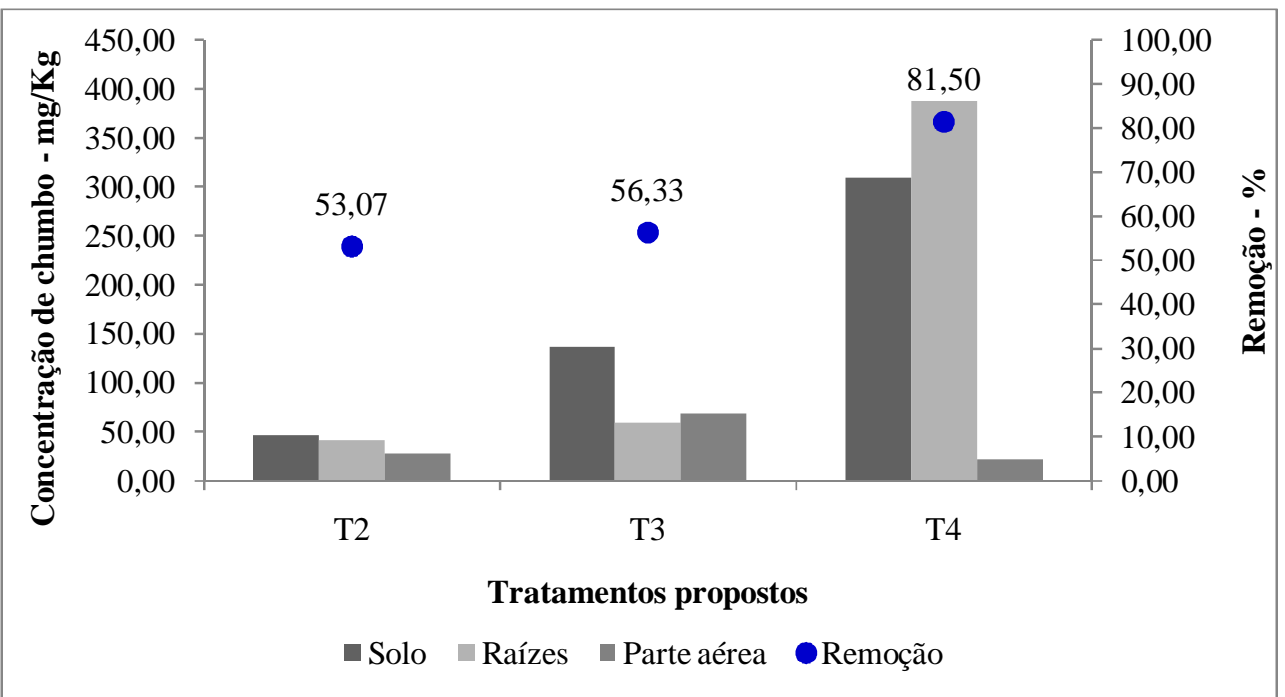

Figura 6: Acompanhamento das concentrações de chumbo no solo, raízes e parte área e percentual de remoção global nos tratamentos propostos.

\section{CONCLUSÃO}

A avaliação realizada nas concentrações de chumbo no lixiviado indicou que ocorreram remoções máximas de $67,42 \%, 87,34 \%$ e $94,74 \%$ para os tratamentos T2, T3 e T4, respectivamente.

A remoção global apresentada por cada tratamento foi de 53,07\% (T2), 56,33 (T3) e $81,50 \%$ (T4), considerando o total de contaminante aplicado durante o período do experimento nos tratamentos.

A retenção do chumbo nos tecidos (sistema radicular, caule e folhas) da mamona indicou que a planta apresentou boa capacidade de bioacumular o chumbo, validando assim a sua utilização em sistemas de polimento de efluentes que foram submetidos a tratamentos prévios.

\section{REFERÊNCIAS BIBLIOGRÁFICAS}

1. ANDRADE, J. C. M., TAVARES, S. R. L., MAHLER, C. F. O uso de plantas na melhoria da qualidade ambiental. São Paulo, Oficina de textos, 2007.

2. APHA, AWWA, WEF. Standard methods for the examination of water \& wasterwater. $21^{\text {st }}$ edition, Baltimore, 2005.

3. COSTA, D. M. A, BARROS JUNIOR, A. C. Avaliação da necessidade do reúso de águas residuais. Holos, ano 21, pp 81-101, setembro 2005.

4. LARCHER, W. Ecofisiologia vegetal. São Carlos, RiMa, 2000. 
5. MATOS, H. S. F. M. Dossiê técnico: cultivo da mamona e extração de óleo. Centro de apoio ao desenvolvimento tecnológico da Universidade de Brasília. 2007.

6. PESSOA, V. M. N, SOUZA, F. C. S., REBOUÇAS, I. G. O biodiesel como elemento de desenvolvimento sustentável no semi-árido potiguar. Holos, ano 23, vol 3, pp 113 $125,2007$.

7. PLETSH, M.; CHARLWOOD, V.; ARAÚJO, B. S. Fitorremediação de águas e solos poluídos. Biotecnologia, ciência e desenvolvimento, ll, p26-29. 1999.

8. ROMEIRO, S., LAGÔA, A. M. M. A, FURLANI, P. A, ABREU, C. P., PEREIRA, B. F. F. Absorção de chumbo e potencial de fitorremediação de Canavalia Ensiformes $L$. Bragantia, Campinas, v. 66, p.327-334, 2007.

9. SILVA, D.N. Degradação fotoquímica de hidrocarbonetos de gasolina em efluentes aquosos. Dissertação de Mestrado, UFRN, Programa de Pós-Graduação em Engenharia Química, Área de Concentração: Pesquisa e desenvolvimento de tecnologias regionais, Sub área: Engenharia Ambiental, Natal/RN, Brasil. 2002. 